\title{
The Quality Lighting Teaching Kit: enlightening our future
}

\section{Constance Walker, Stephen Pompea}

Constance E. Walker, Stephen M. Pompea, "The Quality Lighting Teaching Kit: enlightening our future," Proc. SPIE 9946, Optics Education and Outreach IV, 99460Q (27 September 2016); doi: 10.1117/12.2248490

EDIE Event: SPIE Optical Engineering + Applications, 2016, San Diego, California, United States 


\title{
The Quality Lighting Teaching Kit: Enlightening Our Future \\ Constance E. Walker*a and Stephen M. Pompea ${ }^{\mathrm{a}}$ \\ ${ }^{a}$ National Optical Astronomy Observatory, 950 N. Cherry Ave., Tucson, AZ, USA 85719
}

\begin{abstract}
The U.S. National Optical Astronomy Observatory's Education and Public Outreach group has produced a Quality Lighting Teaching (QLT) Kit, as an outcome of the International Year of Light 2015. The kits are designed around problem-based learning scenarios. The kit's six activities allow students to address real lighting problems that relate to wildlife, sky glow, aging eyes, energy consumption, safety, and light trespass. The activities are optimized for 11-14 year olds but can be expanded to younger and older. Most of the activities can be done within in a few minutes with the exception of the Energy Activity. The activities can be done during class or afterschool and as stations (that the students rotate through) or as stand-alones (one at a time).

All aspects of the program are as ready-for-use. Everything you need for the six activities is included in the kit. Tutorial videos (on the program's webpage) have been created on how to do the activities. They can be found on the webpage, www.noao.edu/education/qltkit.php. Fourteen Google+ Hangouts on Air have been offered, addressing questions on the activities and logistics. Assessments (in the form of pre- and post-surveys for the students and as post-surveys for the instructors) provide learning outcomes and improvements.

Eighty-nine out of 100 kits have been distributed to SPIE, OSA, CIE, IDA and the IAU in 31 countries. The QLT Kit is a stepping-stone to bring awareness to the (younger) public on how quality lighting locally can redress issues like light pollution globally.
\end{abstract}

Keywords: Quality lighting, light pollution, energy consumption, safety, problem-based learning

\section{INTRODUCTION}

Poor quality lighting not only impedes astronomy research and our right to see a starry night sky, but creates safety issues, affects human circadian sensitivities, disrupts ecosystems, and wastes billions of dollars/year in energy consumption. It also leads to excess carbon emissions. How do you change the mindset of society that is used to turning night into day? You educate the next generation on quality lighting.

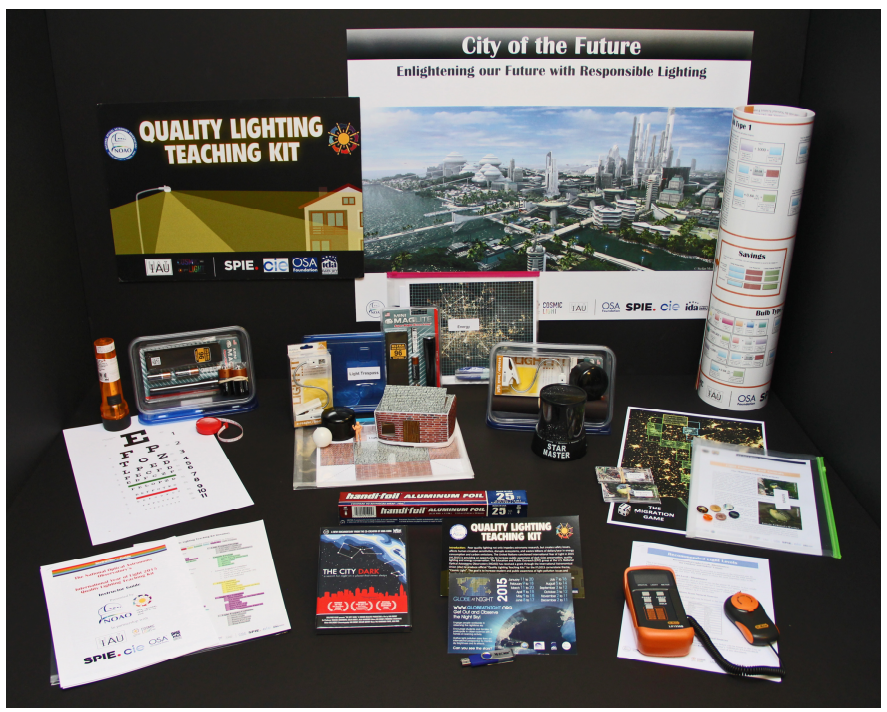

Figure 1. The posters, activity materials and other components in the Quality Lighting Teaching Kit. Image Credit: Pete Marenfeld, NOAO

*cwalker@noao.edu; phone 1520 318-8535; fax 1520 318-8451; noao.edu 
The International Year of Light in 2015 afforded an opportunity to bring awareness to a younger generation of both light pollution issues and lighting solutions based on the principles of quality lighting. Under the sponsorship of International Astronomical Union (IAU) and the Optical Society of America (OSA) Foundation, the Education and Public Outreach (EPO) group at the U.S. National Optical Astronomy Observatory (NOAO) developed and tested an educational kit for ages 11-14 to be used either in classrooms or in out of school programs. The "Quality Lighting Teaching Kit" (Figure 1) provides hands-on/minds-on activities on six common light pollution issues.

\section{THE ACTIVITIES}

The concepts and practices of quality lighting are explored through problem-based learning activities, as well as formative assessment probes. The six activities use quality lighting to solve realistic cases on how light pollution affects wildlife, the night sky, our eyes, energy consumption, safety, and light trespass into buildings. The impact of the kits is amplified by providing professional development using tutorial videos created at NOAO and conducting question and answer sessions via Google+ Hangouts for program instructors. The Quality Lighting Teaching Kit program leverages NOAO EPO's work over the last ten years in lighting and optics education (e.g., "Hands on Optics", the International Year of Astronomy's "Dark Skies Rangers", the IAU "Dark Skies Africa", and Arizona Public Services' "Dark Skies Yuma" programs). ${ }^{[1,2,3,4,5]}$

The premise of the activities is that the instructor is the mayor of a fictitious city in which the students live (inspired by the City of the Future Poster). The mayor has been receiving complaints from citizens of the city, which all have to do with the lights in the city (stated on the Issues Poster). The students have been assembled into 6 different task forces, to determine the underlying problems expressed in each of the 6 complaint categories, as well as to come up with feasible solutions to those problems.

The students start by reading the information presented in their group's poster. The "Now Try This!" section gives instructions for an experiment, game, or activity to complete in order to gain more understanding of the problems with which they are presented. They use the materials in their box and/or envelope to complete the activity. Using what they know along with help from the Problem Solving Poster, the students brainstorm solutions to their problem. The students then carefully consider the implications (both positive and negative) of their solutions as well as any exceptions where their solutions may not work. They determine if there is any other information they need to better understand the problem or have better solutions. This may involve using the links provided or key ideas from the poster to research more about their problem.

\subsection{Energy Poster and Activity}

In this activity, students are given an aerial nighttime view of Houston, Texas, USA with a grid superimposed on top. There are three different colors of lights shown in the image: white (along the highways), yellow (the blobs on the right side are oil refineries), and brown (everywhere else). The students count the number of squares of each colored light to determine how much energy, cost, and carbon footprint this city uses and wastes each night. These values accurately reflect the actual energy usage of Houston as well as the type of lights currently used. If time allows, they will use the Types of Lights handout to determine a more energy efficient scenario by changing the types and/or wattages of the lights or by implementing timers or motion sensors to limit the amount of time the lights are on. The energy, cost and carbon footprint saved can be determined from the difference between the before and after scenarios. All of these calculations can be done on the double-sided Energy Calculation Mat, which can be written on using the wet erase markers or with the accompanying handouts.

\subsection{Safety Poster and Activity}

It is a common misconception that more light is safer; however, this is not always true. While light is needed to see and be safe at night, poorly designed or placed lights can actually be less safe! Poorly shielded or glaring lights provide areas for criminals to hide; criminals also exploit the false sense of security people feel in overly lit areas. In this activity, students will use a lux meter to measure light levels of different scenarios and compare their results to standardized lighting levels. They determine what minimum light levels are needed for a variety of environments to still be safe while conserving energy, cost and carbon footprint. 


\subsection{Animal Poster and Activity}

NOAO EPO staff designed a game for students to explore how light pollution affects animals, specifically birds. In the game they are Kirtland's Warblers, which migrate from the Bahamas to the Great Lakes region of the United States and back again. Along the way, they fly through many major cities. Each year, up to 1 billion birds are killed by crashing into buildings in North America alone. Lit buildings at night cause many of these deaths and injuries. Birds and other animals use the sun or stars to navigate, and the lights can confuse the animals causing them to circle the building and collapse from exhaustion. These issues are explored in the game. A great "Going Further" idea is to have students research and design a game centered on where they live and on an indigenous animal that is threatened by light pollution.

\subsection{Glare Poster and Activity}

As one of the three main types of light pollution, glare is caused by an exposed light bulb. An overly bright bulb can severely impair vision, especially while driving at night. Glare is worse for older adults due to the presence of cataracts and loss of pupil control. In this activity, the students will explore glare from a "headlight" (a capless Mini-Maglite) at night (in a darkened room). With an unshielded light source, students will see how glare affects their ability to read an eye chart 6 meters away. Layers of inkjet transparencies are used to simulate varying degrees of cataracts. The students then explore how cataracts (both with and without a glaring light) can impair their reading ability. The students then come up with and test a solution to redress the problem.

\subsection{Night Sky Poster and Activity}

As a second major type of light pollution, sky glow is caused by unshielded lights from a city shining up into the sky. This light scatters off of dust, water, smog, clouds, and other things in the atmosphere creating a light dome or glow over the city. Sky glow washes out the stars from view; as a result, most people in cities have never seen a dark night sky. The dark night sky has inspired the arts, literature, philosophy, and many other areas of our cultural heritage.

In this activity, the students use a star projector to determine how different kinds of lights and shields affect the number of stars that can be seen. The students try different lights and shields as described in the "Now Try This!" section of their poster to see the effects on the night sky and come up with possible solutions to mitigate the effect of light pollution and test them.

\subsection{Light Trespass Poster and Activity}

The third type of light pollution is light trespass, where light goes where it is not needed, wanted, or intended. The most common example of light trespass is a streetlight shining into a window at night. This can make sleeping (even with curtains or blinds) difficult. The light is not shining where it is supposed to and is trespassing on other property. Light at night, in particular, can have health effects on humans. For instance, blue light (which is common in most LEDs) at night inhibits the production of melatonin. Melatonin is a hormone, which is only replenished when asleep in the dark. Other sources of blue light such as computer, tablet, and cell phone screens before bed also inhibit melatonin production.

In this activity, the students have a 40:1 scale model of a street, complete with a house, a person, a streetlight with a slight drop-down Cobra lens (the book light) and a globe light (Mini-Maglight with the ping pong ball). The students try to recreate the problems voiced in the complaints poster and experiment with the position and angle of the light. They then come up with solutions to keep the light task-oriented (e.g., find ways to shine the light where needed) and mitigate light trespass (e.g., find ways not to shine light where it's not needed).

\subsection{Capstone Presentations}

A key component of problem-based learning is presenting methods and findings to an audience. After the students have completed their research and activities they present this information to the mayor of the city and other task groups. Presentations can take many forms, such as oral (e.g. Powerpoint) presentations, posters, videos, skits, songs, brochures, or pamphlets. After all groups have presented, the instructor leads a discussion in which the groups meld their ideas together. After the presentations and discussion have concluded, the post-assessment is given, mainly to assess student understanding and growth during the project and to gain the teachers' recommendations for improvements. 


\section{DISSEMINATION AND PROFESSIONAL DEVELOPMENT}

\subsection{Dissemination}

One hundred Quality Lighting Teaching (QLT) Kits were built in late 2015. In early 2016, kits were sent to 89 stakeholders in 31 countries (including Argentina, Armenia, Australia, Belgium, Canada, Chile, China, Colombia, Denmark, Egypt, Ethiopia, India, Ireland, Italy, Japan, Jordan, Latvia, The Netherlands, New Zealand, Nigeria, Portugal, Russia, Singapor, South Korea, Spain, Tanzania, Tartarstan, Thailand, United Kingdom, USA and Zambia). The recipients were chosen by our project partners SPIE-The International Society for Optical Engineering, CIEInternational Commission on Illuminations, OSA-The Optical Society, IDA-the International Dark Sky Association, and the IAU OAD-Office of Astronomy Development. This is the first time that all six stakeholders have partnered in educating the public on the importance of quality lighting and its effects on society. Although the kit recipients are experts in the fields of illumination engineering, light pollution mitigation and astronomy education, the kits stood a better chance of actually being used if recipients received extended training on using the kits.

\subsection{Professional Development at a Distance}

The geographic extent of the project precluded the possibility to provide professional development in person to lighting educators. To this same end, tutorial videos on each of the six activities were developed in the spring of 2016. The videos were narrated by our EPO undergraduate students who assembled the kits. The videos posted on the project's webpage, www.noao.edu/educaton/qltkit.php and are seven to fourteen minutes in length. Each video concisely and clearly spells out how to perform the activities using a problem-based learning approach.

The video-based training were augmented by fourteen, hour-long Google+ Hangouts that provided additional internet video-based discussion of the activities. The Hangouts provided an opportunity for kit recipients to interact directly with the kit creators and expert guests who are happy to field questions. A viewer could text questions to the host and live guests. For the convenience of the viewers, two Google+ hangouts were done per topic, one for the Australian/Asian side of the world and one for the African/European side of the world. People in the Americas could attend either.

Reactions from kit recipients who have utilized the tutorial videos have been extremely positive. Peter Offor, Scientific Officer at NASRDA - Centre For Basic Space Science in Nsukka, Nigeria, said, "The video tutorials added flesh to the whole activities. ... going through the videos, I could appreciate each activity better." He added that "the Hangouts I participated in gave me courage to go out teach our younger generation what I have learnt." Other participants felt that the Hangouts helped create an engaged community of teachers using the kits.

The SPIE student chapter from the Universidad Nacional de Tucumán in Argentina organized a meeting before the Hangouts got started in which they watched the tutorial videos and performed the activities. They felt that the explicative videos made everything quicker and easier to learn. This student outreach group also translated into Spanish ten of the eleven posters included in the kit and performed the activities in classrooms.

The tutorial videos and Google+ hangouts have been excellent for reaching the many project partners around the world. Even though alternative ways were created to train on activities at a distance, traditional workshops are still done when possible. An emphasis for NOAO is on areas of astro-tourism surrounding observatories, in La Palma in the Canary Islands (Figure 2), Yerkes Observatory, Hilo, Kitt Peak National Observatory, or in La Serena, Chile near Cerro Tololo Inter-American Observatory. 


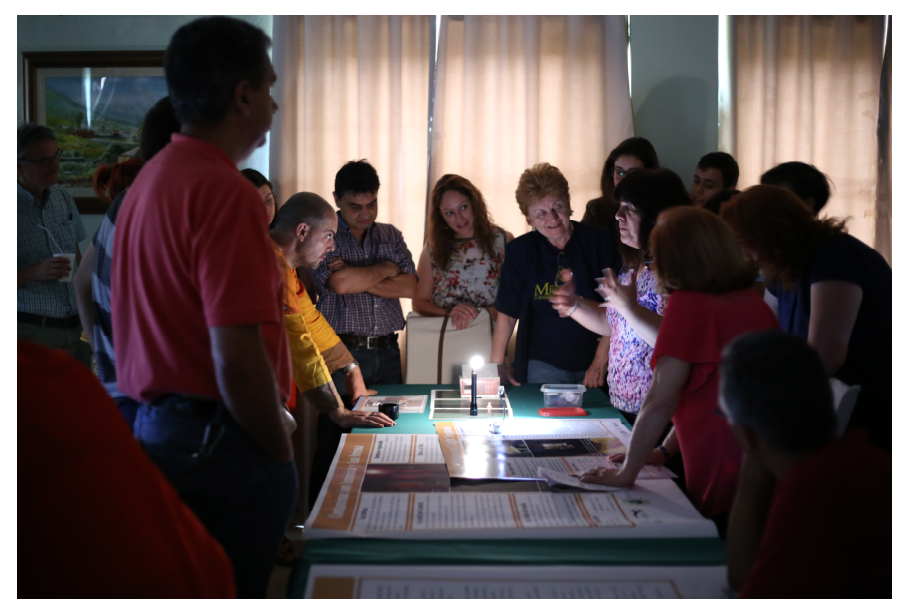

Figure 2. Workshop in the Canary Islands on the Quality Lighting Teaching Kit at the Starlight, Beyond Light Pollution workshop attended by astro-photographers, local teachers, astronomers and staff from the La Palma Office of Tourism. Image Credit: Valentin Grigore, SARM

\section{CONCLUSION}

\subsection{Creating a Legacy}

The funding from OSA Foundation, IAU and NOAO made building the Quality Lighting Teaching Kit possible. The partnership with OSA, SPIE, CIE, IDA and the IAU OAD made the distribution to people that will use the kits possible. The QLT Kit program is the fourth program developed by NOAO Education and Public Outreach to address issues on and solutions to light pollution. We consider it the penultimate kit in this area, internationally unique. From the responses to the vast testing of the kit in 2015 and those received from recipients using the kit thus far, the kit has been wildly successful in its popularity and effectiveness and has been applicable to a wide variety of audiences and ages. The program is becoming a legacy of IYL2015. To continue to make that possible, our next steps are to build another 100 kits (either commercially or through foundation funding), provide subtitles in Spanish (at least) to the tutorial videos and, in some cases, tweak aspects of its activities to locations the kits will be sent. Like the changes in cultural perceptions and actions on smoking and littering, we can bring more awareness on how quality lighting locally can redress light pollution issues globally. Many hands can make light work.

\section{REFERENCES}

[1] Walker, C. E., Pompea, S. M. and Sparks, R. T., "The Development of an Innovative Ecophotonics/lllumination Engineering Education Program for Grades 5-12”, Proc. SPIE 8481, 84810E (2012).

[2] Walker, C. E., Pompea, S. M., "National Education Program for Energy Efficient Illumination Engineering", Proc. SPIE EcoPhotonics 8065, 80650Q (2011).

[3] Walker, C. E., Luginbuhl, C. B., Wainscoat, R.J., "Lighting and Astronomy", Selected Papers of the Light and Lighting Conference 2009 with Special Emphasis on LEDs and Solid State Lighting (CIE x034:2010), 173 (2010).

[4] Walker, C. E., Pompea, S. M., Sparks, R. T., Dokter, E. F. C., "Teaching illumination engineering using light pollution education kits", Proc. SPIE 7783, 77830H (2010).

[5] Luginbuhl, C. B., Walker, C. E., Wainscoat, R. J., "Lighting and Astronomy", Physics Today, 62, Issue 12, 32 (2009). 